\title{
Occupational Health and Safety in Small Enterprises: A Field Study in the Western Region of Saudi Arabia
}

\author{
Nayef Salah Al-Ghamri ${ }^{1}$ \\ ${ }^{1}$ Faculty of Economics and Administration King Abdulaziz University, Jeddah, Saudi Arabia \\ Correspondence: Nayef Saleh Al-Ghamri, Faculty of Economics and Administration King Abdulaziz University, \\ Jeddah, Saudi Arabia.
}

Received: May 5, 2017

Accepted: September 19, 2017

Online Published: September 25, 2017

doi:10.5539/ibr.v10n10p182

URL: https://doi.org/10.5539/ibr.v10n10p182

\begin{abstract}
This research aims at familiarizing the business environment in Small Enterprises (SEs) in the Western Region of Saudi Arabia with occupational accidents that occur due to the lack of interest and belief of the enterprise administration in this issue, a trained supervisor, and the non-compliance of workers with the rules and regulations of Occupational Health and Safety (OHS). It also demonstrates the role of Civil Defense in reducing the number of such accidents. The research makes some recommendations that may contribute to improving the OHS level. A survey questionnaire was distributed among 170 employees, supervisors, and owners of SEs. This survey was conducted before the development of questions required for the study. The results of the study have shown that there is a statistically significant correlation between the reduction of OHS and the administration's belief in adopting and implementing OHS systems. Also, there are statistically significant differences between the reduction of OHS accidents, the workers' personal characteristics, their technical qualification and training, and their manners and awareness. Moreover, the results have shown that workers do not care about the use of OHS means, and are not willing to use modern technology. The study recommends that the enterprise administration should pay attention to adopting OHS systems and creating an accident-free work environment. This is in addition to working side by side with workers, encouraging them to use the OHS means, giving them their rights, appointing trained supervisors, cooperating with Civil Defense especially in cases of any accidents, using modern technology, and getting insurance coverage for workers and the enterprise assets.
\end{abstract}

Keywords: small enterprises, OHS, occupational accidents, civil defence, Jeddah

\section{Introduction}

\subsection{Background}

When the industrial revolution began in Europe, many of the peasants moved to cities to escape the bondage they had received from the feudalists, but their work in factories put them at risk of receiving many occupational injuries as a result of their lack of knowledge of handling machinery and not standing up for their rights to improve the work environment. Factories were full of different kinds of risks because of the lack of culture of risk awareness among workers. It was a common practice that if a worker gets an accident by his/her own mistake, the employer would not bear any responsibility. When accidents increased alarmingly, and the industrial society began to talk about them, laws were enacted, some of which were OSHA ACT, and (OSHA, 2012) in 1972. Consequently, factory owners started to improve their factory working conditions and became committed to compensate the injured, thus, reducing the number of injuries. More than forty years have passed since these laws were enacted, but accidents still exist. In 2015, the number of deaths in the USA reached 4,500 workers in addition to 4.1 million injuries. This has forced the official authorities to develop programs for preventing occupational accidents, which are based on the principle of convincing the administration to assess its OHS programs, training the staff to predict and prevent accidents, and considering OHS as a strategic goal of the enterprise (Legg, Olsen, Laird and Hasle, 2015). As for SEs, government agencies have set up the laws and statutes that regulate the work of those enterprises and require them to have safety equipment in place, take insurance for workers and the enterprise assets, and give workers their rights by providing an appropriate work environment. As a result, local, regional, and international interest in OHS has increased (Hasle \& Limborg, 2006). In Saudi Arabia, we can say that many businessmen focus on commercial projects, whereas they have little interest in industry and dealing with machinery. However, in the last two decades, some businessmen have 
moved to the industrial professions. Since the financial capabilities of SEs are modest, some machines may be old and used, workers do not have experience in operating them. Also, these workers are unaware of practicing safety means, and the work environment is often inappropriate. Now, the official bodies necessitate that such enterprises adapt themselves to the culture of industry and utilize modern technology in every way to change the policies of OHS and also pay great attention to the importance of safety means. This is the responsibility of the enterprise administration, in addition to adhering to safety standards, to change the workers' manners, educate them, encourage their participation in safety matters, build confidence among them, and train them to consider safety as one of the most important values and objectives of the enterprise. The official bodies also strive to promote the culture of safety among SEs as it is believed that they still have not reached the required level of awareness because the proportion of casualties in SEs is higher than that in large enterprises (Legg, Laird, Olsen, \& Hasle, 2014). Additionally, this will enable the workers to work in a safe environment away from injuries and deaths.

\subsection{Literature Review}

Several studies have been conducted in the field of OHS in the last two decades. Al-Subaie (2013) conducted a field survey t explore the level of satisfaction among workers at King Fahd Medical City in Saudi Arabia and found that OHS played a significant role in their responses. Al-Sharif (2001) conducted a field study in which he explored industrial accidents that may occur in factories in the city of Dammam, Saudi Arabia and he found that the owners of workshops and factories have interest in the awareness of the importance of the availability of OHS equipment amongst emplyees. Al-Moghni (2006) explored the OHS aspects and procedures at a sample of 258 industrial facilities in Gaza strip and found that those facilties lack the the propoer safety awareness and that the academic qualifications of workers have their effect on reducing the occurrence of industrial accidents. A study that was conducted by Taha and Elia (2012) in the city of Assiut in Egyt to identify the shortcomings in the OHS issues at Al-Kawthar industrial area, concluded that there is a need to establish a cultural program for workers and professionals and to raise the protection awareness among workers, managers, and the industrial community in addition to imposing penalties by the managers on workers who do not comply with OHS regulations. Khalif (2008), on the other hand explored the role of technology and its impact on industrial accidents and relations at Badush Cement Laboratory in Northern Iraq. He concluded that concluded that it is necessary to pay attention to workers' qualifications in the OHS field and to give this the highest consideration. In an attempt to explore the accidents at educational buldings in Egypt, Abdulraouf. (2002) conducted a study in which he concluded that the main causes of fires and accidents are the methods of construction as the architects did not follow modern fire control methods such as the shape of the building and having appropriate exits outside the buildings to avoid smoke from fire, proper ventilation, and proper fire extinguishing systems. Dejoy, Schafer and Wilson (2003) conducted a research study in which they aimed at identifying the important factors in achieving appropriate work conditions free from occupational accidents. They found that senior administration's belief in OHS measures in any enterprise has the first and fundamental role in reducing occupational accidents. An older study by Heinrich, Petersen, Roos, Brown and Hazlett (1980) conducted a study aimed at tackling occupational accidents by examining 500 accidents. The study concluded that the most important problems resulting from workplace accidents, which are stopping production, lost time of paramedics, supervisors, and workers, damage to machinery and equipment, wage paid to a worker who is not working, chaos in the workplace, low morale of the worker and other workers; and compensation and treatment costs. A different approach was taken by Tucek (2013) in which he attempted to highlight the benfits of protecting the workers at industrial establishments in which he made several recommendations including awareness and regular updates on OHS issues. Moeti-Lysson \& Boy (2011) explored OHS issues at small and medium sized enterprizes in Botswana in which they concluded that the education and awareness of employees and administration have a great role in protecting the enterprise's personnel in the workplace from work accidents and infection that they may catch.

\subsection{OHS Department}

As a service unit in the enterprise, the OHS Department has undergone several stages of development and growth. The importance of OHS has increased and its role in the organization has multiplied. It has de veloped the means and tools it uses to cope up with the rapid and steady progress of the means of production to be in line with the complex equipment that exists in most factories in the modern time. OHS programs are the rights of workers that must be provided in organizations to achieve the individual objectives of maintaining the workers' safety and create a proper and risk-free work environment. This further contributes to increasing productivity and reducing costs. The technological development and the internal and external environmental changes have placed many burdens and responsibilities on organizations, especially regarding maintaining workers' health and 
preventing them from diseases and accidents, compensating them for damage caused by the work environment, and creating safe working conditions. By assuming these responsibilities, the organization can achieve competitive advantages.

\subsection{Definition of SES}

The definition of SMEs varies by location, quality of work, and quality of administration (Park et al, 2013). According to ILO (2015), any enterprise of more than 10 and less than 100 workers is classified as a small one (SE). In Saudi Arabia, an enterprise of less than 20 workers and a capital of less than $\$ 2,500,000$ is an SE. Although the number of workers and capital are the fundamental components of the definition. We note that jewelry business needs more capital while agricultural business needs a larger number of workers. Such projects absorb a small proportion of the market and are characterized by a solitary management style. SEs are the backbone of many of the Third World economies. They provide job opportunities for large number of young people and income for the Saudi family. They are considered a period of incubation for large enterprises. They are inexpensive in their establishment and have small invested capital and a rapid payback period. They may finance large industries in terms of productive integration. Foreign workers dominate the Saudi workforce in this sector because of the lack of benefits and incentives like those offered in the government sector. Saudi businesswomen face several challenges in doing their jobs in SES (Ghamri, 2016).

\subsection{OHS Management Concept}

The concept of OHS Management refers to those regulatory procedures aimed at protecting workers in industrial and service establishments, preventing them from accidents and infectious and non-communicable diseases which they are exposed to during performing their daily duties (Abbas, 2003).

\subsection{Costs of Occupational Accidents and Injuries}

Injuries have a negative impact on the staff, the enterprise, and community. Workplace accidents may cause machinery and equipment breakdowns, low production levels, and low competitiveness, over and above the cost of repair or replacement. As for the injured worker, he will suffer from his chronic disability, his low morale, his dissatisfaction with the work environment, and his loss of salary. Society is also affected as the family of the injured worker will face consequent social and marital problems of low income that may lead to separation (Al-Sabaawi, 1998). The economic problems may appear in the exit of some companies from the market causing the decline in profits or bankruptcy due to fires in buildings or warehouses, especially if there is no insurance on the company's assets.

\subsection{Types of Occupational Accidents and Injuries}

Wounds are the most common injuries in the workplace and are associated with some fractures in case the injury is serious and the fractures are in the hands, the legs, the head or the spine. These injuries and fractures may cause partial or total disability, and they sometimes become fatal. These injuries often occur without warning. Workers in these areas can be protected by putting on means of protection used for human body organs. For example, workers may use helmets to protect the head, gloves to protect the hands, masks to protect the respiratory system, goggles to protect the eyes in the case of welding and cracking, and ear protection devices in the case of loud sounds, and shoes to protect feet from coarse floors and electric shocks. Occupational accidents are not the only ones that occur to workers, but there are also occupational diseases that may afflict them. For example, doctors in hospitals are occupationally exposed to a variety of infectious diseases transmitted by viruses or due to their contact with patients such as immunodeficiency diseases, tuberculosis, malaria and some infectious diseases transmitted from animals and birds (Bird flu and SARS). Likewise, the exposure of technicians and doctors to infrared radiation may lead to cancer. Laboratories are often built outside the hospital building or in the basement. Workers may be exposed to certain pulmonary diseases because of inhaling or touching some chemicals. Diseases may be due to high temperatures; as in the case of those working in iron smelters, or building workers during summer time in Saudi Arabia, where temperatures are sometimes above $50^{\circ}$ C.

\subsection{OHS Objectives}

The main objectives of OHS are summarized in four axes:

- The human axis that aims to help workers avoid injuries, accidents, and diseases by creating an appropriate and risk-free work environment.

- The economic axis that is related to the company's asset protection from damage and fire, and all that is related to costs such as the cost of replacing machines, the cost of compensating the injured worker, 
and the cost of appointing a replacement for him/her.

- The productive axis falls within the temporary and permanent equipment and machinery failure and the creation of the appropriate production environment.

- The cultural axis is represented by spreading the culture of safety, workers' commitment to OHS systems, and the senior administration's support for the principles of OHS. It is also represented by supporting workers materialistically and morally, improving the work environment, and training workers on new technology (Al-Ghazawi, 2005)

\subsection{Causes of Occupational Accidents and Diseases}

There are several reasons for occupational accidents, including disregarding the importance of the means of protection, working long hours on machines and equipment, lack of concentration or preoccupation with other things due to a worker's personal problems, and lack of awareness or the belief that the accident will not happen to them, and accepting doing dangerous work. Lingard's study (2015) proved that after training those workers, their way of thinking changed, and now most of them believe that they are at risk and refuse to do dangerous work. In some cases, accidents may occur because the worker may accept doing any new work without having any experience, or as a result of overcrowding, lack of space, and not using advanced safety devices (Al-Aqayelah, 2003).

\subsection{Work Environment Safety and Precautions to Avoid Work Accidents}

Dangerous and unhealthy environment includes uncleanliness of the place, high temperature, noisy sound, poor lighting, spread of dust, absence of ventilation fans, unavailability of proper early warning systems, or unavailability of guidance and instructions. Ensuring work environment safety includes alerting workers to hazards in the workplace, providing medical aids, taking precautions to prevent future fire hazards, obligating each facility to notify the Civil Defense of any accident within twenty-four hours of its occurrence. As for the prevention of infectious diseases, workers should be vaccinated against such diseases and should be treated if they catch these diseases, and medical records for all workers should be filed (Jaber, 2001).

\subsection{Harassment and Offensive Conduct in the Workplace}

Incidents of offensive conduct against workers, managers and doctors by employees or clients have become very common these days. Saudi businesswomen may face racial harassment by their employees who consider women inferior (Ghamri, 2016). Therefore, the administration should pay attention to and reduce violent crime in the workplace which falls within the employees' safety, write investigation reports on the causes of the accident and how it is handled, and make a firm commitment to the employees' safety (Willicam, 1996)

\subsection{Measuring the Effectiveness of the Safety Program}

The effectiveness of the safety program can be measured by the frequency of injuries and severity of injuries, such as;

1. Frequency of injuries: It means the number of injuries, and it is defined as the number of disabling injuries within one million work hours at the facility.

2. Severity of injuries: It aims at knowing the extent of severity of injury, and it is defined as the total number of days that represent the time lost within one million work hours at the facility.

\subsection{Causes of Warehouse Fires and Prevention Methods}

\subsubsection{Causes of Fire}

I. High temperatures in summer may lead to many problems with exposed reservoirs. For example, leaving rice straw exposed to the sunshine will ignite it.

II. The oldness of the building and its limited storage capacity lead to stacking of goods above each other, which makes it difficult for fire engines to enter the warehouse. Poor connections and electrical wiring can also lead to fire.

III. The supervisor may be unable to communicate with the expatriate workers; which leads to disputes between him and those workers and the workers' lack of sense of belonging and loyalty to the project. This in turn leads to negligence in applying protection measures for the building and the enterprise assets.

\subsubsection{Prevention Methods}

Provision of: fire extinguishing systems, early warning systems, rear exits, appropriate ventilation systems, and automatic spontaneous lighting. This is in addition to the use of furniture treated with fire retardants and 
preventing smoking among employees, which is one of the main causes of fire, (Fry, 1996) and (Merrily, 1992),

\subsection{The Research Problem}

First, the research problem is that many SEs do not care about the OHS culture among their employees and their lack of interest in creating proper work environment (Cunningham et al, 2014) and (Ghamri, 2016). This is obvious in dealing with expatriate workers, who make up the largest proportion. Most of them come from poor countries. Due to the lack of academic and social backgrounds, these workers are unable to claim their rights for health insurance. In addition, their willingness to work long hours leads to stress and contributes to the increase of injuries (Park \& Others 2013). Most SEs do not have any reports of injured workers. Second, SEs do not care about applying local, regional and international standards in OHS procedures because this represents a financial burden on these enterprises. Hence, the higher the financial position of the company, the higher the safety level (Lin \& Mill 2001). Accordingly, the research problem lies in the lack of seriousness of the owners of SEs to realize the importance of OHS means, evading the Civil Defense in the provision of these means, lack of the workers' awareness of their importance, and workers' not claiming their rights.

\subsection{The Research Study Hypotheses}

The study was guided by the following hypotheses:

- There is a significant correlation between the reduction of occupational accidents and the administration's belief in adopting OHS systems.

- There are statistically significant differences between the reduction of occupational accidents and the personal characteristics of workers in terms of technical qualification, training, manners, awareness, and stress.

- There is a significant correlation between OHS accidents and the employees' morale, their performance level, job satisfaction, and productivity.

- There is a statistically significant correlation between the reduction of OHS accidents and the use of OHS means.

- There is a statistically significant correlation between the improvement of OHS and the use of modern technology.

- There is a statistically significant correlation between OHS accidents and the economic and social damage.

- There is a statistically significant direct relationship between the effectiveness of safety, security, and fire procedures in SEs.

- There is a statistically significant direct relationship between the effectiveness of the procedures of safety, security, external oversight, and Civil Defense.

\subsection{The Research Objective(s)}

This research study aims at identifying OHS acidents that occur inside SEs and ways to prevent them and protect the workers at those industrial SEs.

\subsection{Significance of the Study}

The importance of the study lies in the scarcity of research about OHS in SEs in Saudi Arabia that deals with health and safety as a means and not as an end. It can be said that this study is one of the few studies that deals with OHS in all aspects in terms of culture of safety and individuals' awareness. Additionally, the study addresses the number of foreign workers in Saudi Arabia, checking their educational and social backgrounds, and investigating their awareness of the implementation of OHS systems. Furthermore, taking into consideration the importance of SEs, which represent $85 \%$ of the number of all enterprises and their relationship with OHS, they have not been given the proper time and attention neither by researchers in management science nor by businessmen in SEs.

\section{Method}

The analytical descriptive approach has been used in the study.

\subsection{Study Sample}

The random sample was used in this study, and 170 questionnaires were distributed to SEs owners, employees, and some OHS supervisors. The respondents were the individuals who had a desire to cooperate. The questionnaire items were close-ended questions along with an open-ended question at the end to provide opinion. 


\subsection{Data Collection}

Primary data was collected by distribution of the questionnaires to businessmen, workers, and supervisors in SEs. Secondary data were collected by searching in libraries and on the Internet for specialized books in the field of OHS. Some interviews that were conducted with businessmen contributed to coming up with some important ideas on the subject of OHS.

\subsection{Study Instrument}

The questionnaire was designed considering the research objectives, and the de velopment of questionnaire items and their design made use of many questionnaires of previous research studies. A pilot survey was conducted and presented to some arbitrators in the Faculty of Economics and Administration at King Abdulaziz University to verify the veracity of the face validity and content validity of the questionnaire where some necessary amendments were made. Statistical software (IBM SPSS 23) was utilized to analyze the data.

\subsection{Research Limitations}

- Human limitation: Only owners of SEs and workers in these enterprises were selected. Samples of the pilot questionnaire were distributed. Then, after improving the questionnaire, it was distributed to the specific number of the participants for the study.

- Time limitation: Reading books and magazines, browsing the Internet, distributing and analyzing the questionnaires, and writing the research took nearly a full year.

- Place limitation: The study took place in the Western Region in the city of Jeddah as the first commercial center in the Kingdom of Saudi Arabia and the city of Yanbu as the main center for industries that has many SEs.

- Objective Limitation: The study focused only on OHS in the SEs sector, and it is concerned with recognizing the laws, regulations, and OHS means.

- Difficulties of the study: Lack of interest of some businessmen in the importance of research in general; and not giving sufficient time to the interview, and responding to the questionnaire quickly and without any concentration or interest were the problems faced during data collection. Some businessmen sometimes refused to fill out the questionnaire either due to the fear of the study area or lack of desire to cooperate.

\subsection{Instrument of the Study}

The researchers used a questionnaire as an instrument to collect data as the questionnaire is an appropriate tool for collecting information, data and facts related to a particular reality (Obidate et al., 2011).

This study is based on two phases; the first phase is the pilot study to test the questionnaire designed to collect raw data by measuring its validity and reliability. In order to do so, the researcher distributed the questionnaire on a limited sample (29) of the study.

The questionnaire consisted of 55 items distributed among the variables shown in the following table: Table (1) shows the study variables and their items: 
Table 1. Main Study Variables and their items

\begin{tabular}{|c|c|}
\hline Study variables & $\begin{array}{l}\text { Number of } \\
\text { items }\end{array}$ \\
\hline \multicolumn{2}{|l|}{ First: Independent variables } \\
\hline $\begin{array}{l}\text { 1. Management's conviction which requires commitment to implement safety measures and to carry out } \\
\text { appropriate activities and procedures to meet these requirements in order to achieve an accident-free working } \\
\text { environment. }\end{array}$ & 14 \\
\hline $\begin{array}{l}\text { 2. Awareness and training which requires improving awareness, training and qualification le vels to spread the } \\
\text { culture of safety among employees, supervisors and administrators }\end{array}$ & 9 \\
\hline $\begin{array}{l}\text { 3. The use of technology which requires encouraging workers to use technology to develop and improve } \\
\text { means of security and safety }\end{array}$ & 5 \\
\hline $\begin{array}{l}\text { 4. The participation of employees requires that each worker participates in every activity related to security } \\
\text { and safety, as well as encouraging him/her to use expertise and intellectual abilities in making suggestions that } \\
\text { may help in the field of security and safety. }\end{array}$ & 6 \\
\hline 5. The effectiveness of security, safety and external control procedures & 7 \\
\hline \multicolumn{2}{|l|}{ Second: Dependent variables } \\
\hline $\begin{array}{l}\text { 1. Limiting work injuries among w orkers which includes a commitment to follow the procedures of safety and } \\
\text { security systems. }\end{array}$ & 7 \\
\hline $\begin{array}{l}\text { 2. Achieving employees' satisfaction, rais ing their morale and level of production and reducing work turnover } \\
\text { rate include achieving good relations with employees and taking care of their rights. }\end{array}$ & 2 \\
\hline 3. Preventing fires in firms and reducing economic and social costs. & 7 \\
\hline
\end{tabular}

Source: Prepared by researchers

Thus, the study questionnaire included 55 items. In addition, the questionnaire contained 4 special variables related to the sample characteristics. These characteristics include years of experience, age and educational qualifications.

\subsection{Validity of the Questionnaire}

\subsubsection{Face Validity}

To validate the tool and its suitability for collecting raw data, several procedures have been used among which is validity (face validity). The researcher introduced the questionnaire in its initial form to a number of specialists in the field of scientific research to provide their feedback in terms of comprehensiveness and statement of items, diversity of content, and appropriateness.

\subsubsection{Internal Validity}

The researcher verified the validity of the questionnaire in the pilot study by randomly choosing a sample of 29 out of the study community to measure the internal validity of the tool's four axes with its total score by calculating the correlation between each axis and the total score of the tool. Table (2) shows that correlation

Table 2. Correlation coefficients between the score of each axis with the total score of the instrument

\begin{tabular}{lll}
\hline \multicolumn{1}{c}{ Axes } & $\begin{array}{l}\text { correlation } \\
\text { coefficients }\end{array}$ & $\begin{array}{l}\text { Level of } \\
\text { significance }\end{array}$ \\
\hline $\begin{array}{l}\text { Axis 1: The management's conviction of implementing occupational safety } \\
\text { measures }\end{array}$ & $0.918^{* *}$ & 0.00 \\
Axis 2: workers' morale, awareness, training and qualification. & $0.968^{* *}$ & 0.00 \\
Axis 3: The use of modern technology & $0.813^{* *}$ & 0.00 \\
Axis 4: economic and social damages & $0.696^{* *}$ & 0.00 \\
\hline
\end{tabular}

** indicates that correlation coefficient is statistically significant at $(0.01)$

Table (3) shows that all of questionnaire's axes are highly correlated with its total score. Thus, all axes have a high degree of validity as correlation coefficient ranged between (0.696-0.918), and are statistically significant at (0.01) level.

\subsection{Reliability of the Study Instrument}

\subsubsection{Reliability of the Study Instrument by Split Half}

The researcher calculated the reliability of study instrument by using the split half method. Correlations between the total scores of even and odd items were calculated using Pearson correlation coefficient and then were corrected using Spearman Brown coefficient. Pearson correlation coefficient was (0.950), while Spearman Brown coefficient was (0.949); therefore, the study instrument is highly reliable. Thus, the procedures of building the study instrument are correct. 
Table 3. Reliability coefficients of the study instrument by split half method

\begin{tabular}{ll}
\hline Coefficient & value of corre lation \\
\hline Pearson coefficient & $0.950 * *$ \\
Spearman coefficient & $0.949 * *$ \\
\hline$* *$ Indicates that correlation coefficient is statistically significant at $(0.01)$ level &
\end{tabular}

** Indicates that correlation coefficient is statistically significant at $(0.01)$ level

In addition, the researcher calculated the overall reliability of the instrument and its axes through using alpha Cronbach coefficient, as shown in table (4). Value of reliability coefficients indicate that all axes are highly reliable as the overall reliability was (0.937), which assured the researcher about the accuracy of constructing and stating axes and items.

Table 4. Alpha Cronbach coefficients for the overall reliability of the instrument and its axes

\begin{tabular}{lll}
\hline Axes & $\begin{array}{l}\text { Number } \\
\text { of items }\end{array}$ & $\begin{array}{l}\text { Correlation } \\
\text { coefficient }\end{array}$ \\
\hline $\begin{array}{l}\text { Axis 1: The management's conviction of implementing occupational safety } \\
\text { measures }\end{array}$ & 29 & 0.870 \\
Axis 2: workers' morale, awareness, training and qualification. & 15 & 0.864 \\
Axis 3: The use of modern technology & 6 & 0.755 \\
Axis 4: economic and social damages & 5 & 0.666 \\
Total reliability & 55 & 0.937 \\
\hline
\end{tabular}

\subsection{Statistical Calculations}

The researcher used descriptive statistical methods, which were represented in the frequencies and percentages, to describe the sample of the study according to the demographic characteristics. Statistical means and standard deviations were also used to measure the participants' response about items. Furthermore, the researcher used t-test and ANOVA to test the significance of differences between the respondents' viewpoints about the study axes due to differences in their demographic variables.

Table 5 shows the criterion of judging on the participants' responses about the study axes according to the five-dimensional Likert scale used in the study.

Table 5. Criterion of judging the results according to the five-dimensional Likert scale

\begin{tabular}{ll}
\hline \multicolumn{1}{c}{ Scale } & Grade \\
\hline $1-<1.80$ & Very weak \\
$1.80-<2.60$ & Poor \\
$2.60-<3.40$ & Medium \\
$3.40-<4: 20$ & High \\
$4.20-5$ & Very high \\
\hline
\end{tabular}

\subsection{Analysis and Interpretation of Datas}

2.9.1 Description of the Sample According to Demographic Variables:

The study sample was described according to their demographic characteristics; years of experience, age and educational qualification. Results showed that the majority $(42.5 \%)$ of respondents have less than 5 years of experience, $24.2 \%$ have (11-20) years of experience, $12.4 \%$ have (6-10) years of experience, $11.1 \%$ have (31-40 years) years of experience, while $9.8 \%$ have (21 to 30 ) years of experience.

Thus, the majority $(42.5 \%)$ of respondents have less than 5 years of experience and that enhances their probability of being injured at work due to the inadequacy of occupational security and safety instructions for them. 


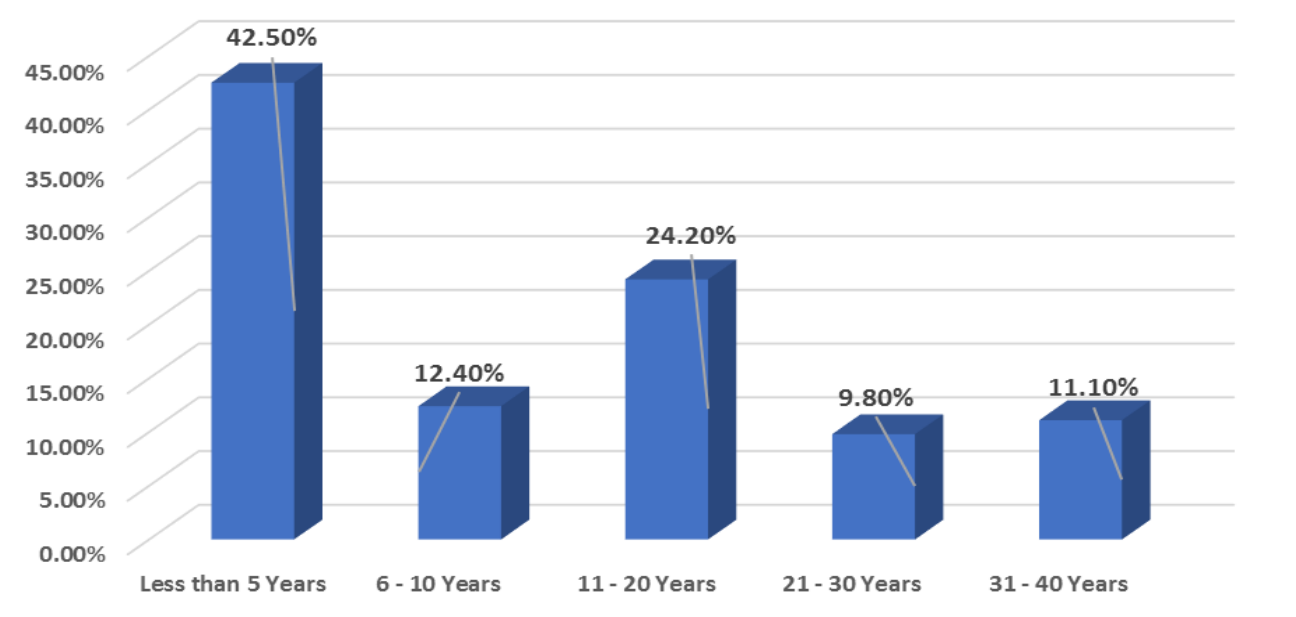

Figure 1. Description of the sample according to years of work experience

Regarding the description of the sample according to the age, results showed that most respondents are youth, as $71.3 \%$ of them are under the age of 40 . Consequently, the owners of small projects are obliged to keep the workers away from work injuries or occupational accidents.

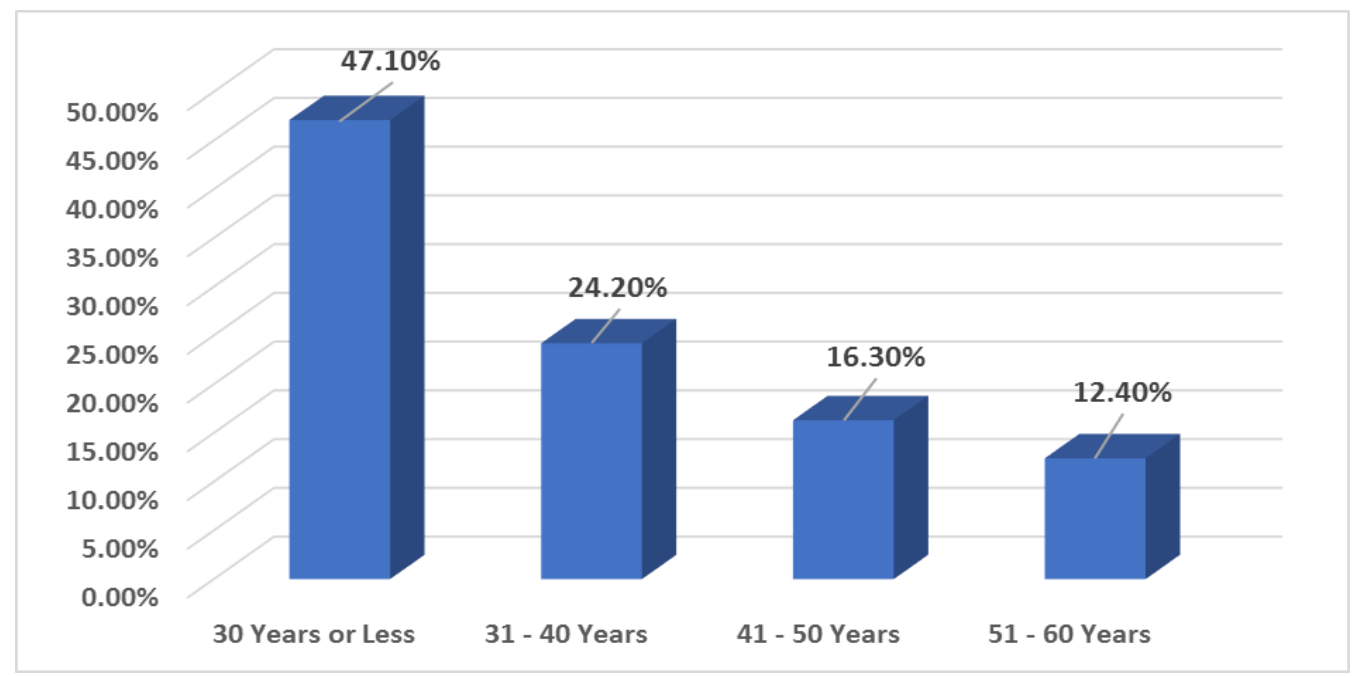

Figure 2. Description of the sample according to age

Regarding the description of the sample according to their educational qualifications, results showed that the majority (62.7\%) of participants have completed their high school only, while $37.3 \%$ have a bachelor degree, and that match with the nature of the work they carry out in these projects.

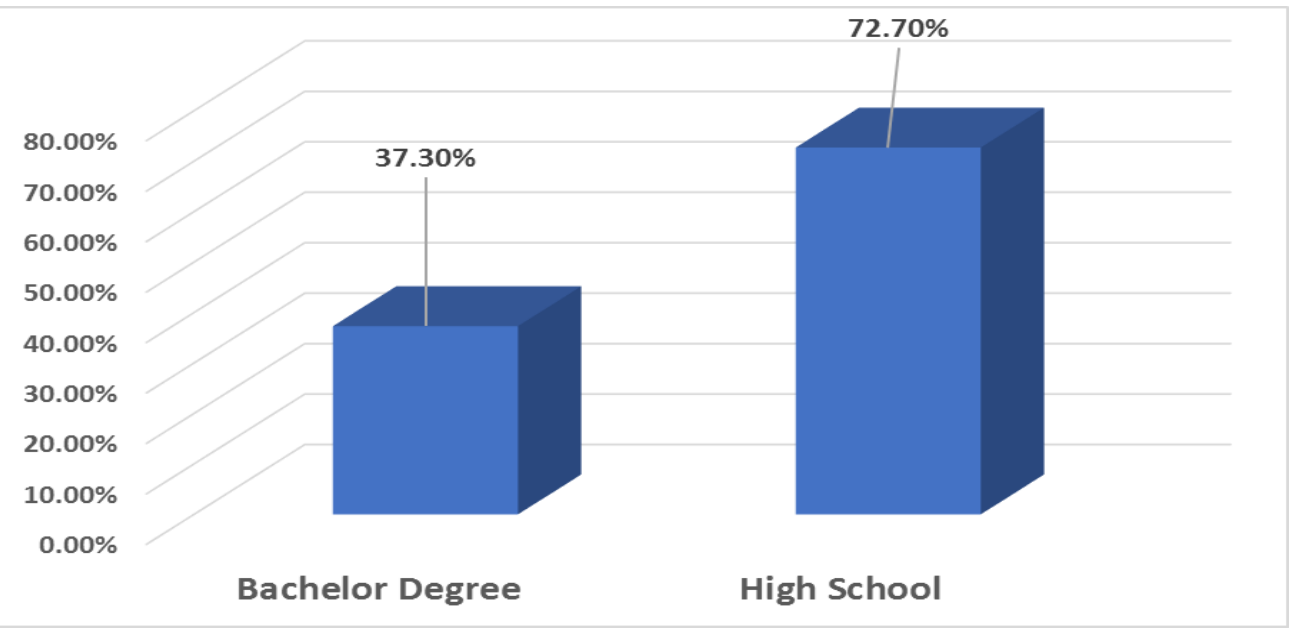

Figure 3. Description of the sample according to their educational qualifications 


\subsubsection{Second: Descriptive Statistics for the Participants'Responses}

In this part, the researcher tries to analyze and to interpret the participants' responses about the study axes and items. Weighted arithmetic mean was used as a criterion for assessing the participants'responses, as follows:

\subsubsection{Axis 1: Implementation of Security and Safety Measures in Small Enterprises}

Results of analyzing and interpreting the participants' responses about the most prominent safety measures that significantly limit the occurrence of occupational accidents, showed that the following procedures are the most important ones;

- Security and safety tools must be provided

- Laws and regulations of security and safety must be complied with.

- workers must not work without safety tools

- The presence of examination and maintenance schedules reduces accidents.

- First aid must be provided at the facility.

- Assigning workers according their abilities

- Setting special instructions

- External authorities concerned with security and safety must supervise the project

- The existence of an agreement with a hospital or medical staff contributes to the treatment of urgent cases

- System, Health and Safety Management Certificate

The results also indicated that failure to follow security instructions significantly leads to accidents as well as the following reasons:

- Operating old or non-maintained equipment

- Robbery and sabotage

- Poor lighting and ventilation

- High temperatures

- The old buildings

- Lack of emergency exits

- Short circuit resulted from old electricity connections

- Lack of interest in industrial security rules

- The absence of a competent authority for security and safety in the project

2.9.2.2 Axis 2: The Role of Workers' Training, Rehabilitation and Awareness in Reducing Occupational Accidents

By analyzing participants' responses, the researcher concludes that the most important factor that highly limits injuries is the management and workers' awareness to develop safety regulations and laws. In addition, results indicated that the lack of staff's awareness about occupational health highly increases accidents. Furthermore, results showed that work accidents have many negative effects either on the worker or on the production process or even on the co-workers.

\subsubsection{Axis 3: Economic and Social Damages of Industrial Security Incidents}

Regarding economic and social damages for industrial security accidents, results showed that these accidents have impacts on the worker, the family, and the community; in addition to, damages that affect the project's buildings and the surroundings.

\subsubsection{Axis 4: The Impact of Using Modern Technology in Reducing Accidents}

Results showed that there are five indicators for the importance of using of modern technology in reducing accidents and work injuries. The most important indicator is the existence of a fire alarm connected to the Department of Fire in the event of fires occurring outside working hours. Second, analyzing the causes of accidents by using modern methods such as pictures, and videos. Third, treating the causes. Fourth, writing reports in order not to repeat accidents. Finally, using early warning systems highly contribute to the reduction of accidents.

\subsubsection{Third: Validation of the Study Hypotheses}

In this part, the researcher tackles the results of validating the study hypotheses. Pearson correlation coefficient 
was used to test these hypotheses, as described below:

Hypothesis 1 stated that there is a statistical significant correlation between the reduction of occupational accidents and the management's conviction of applying security and safety systems. Results showed that the value of the correlation coefficient between the reduction of occupational accidents (dependent variable) and the management's conviction of applying security and safety systems (Dependent variable) was (0.626), and that value is positive and statistically significant at (0.01) level. As a result, the researcher concludes that there is a positive correlated relation between the management's conviction of applying security and safety systems and the reduction of occupational accident in small projects, and that conviction protects workers from work injuries.

Hypothesis 2 stated that there is a statistical significant relationship between the reduction of occupational accidents and workers' personal traits such as technical rehabilitation, training, behaviors and awareness. Results showed that there is a statistical significant relationship at (0.01) level. This result showed how independent variables, such as workers' technical rehabilitation, training behaviors and awareness, affect the reduction of occupational accidents and small projects. Accordingly, technical training and rehabilitation programs on using the security and safety procedures as well as workers' behavior and awareness effectively contribute to the reduction of occupational accidents. Consequently, this prevents injuries that have social and economic consequences not only on the worker and his family, but also on the community as injurers cause losing community's economic productive resources.

Hypothesis 3 stated that there is a statistical significant relationship between security and safety accidents and employees' morale and their level of performance, satisfaction and productivity efficiency and the results confirmed this hypothesis. The higher workers ' morale and satisfaction are, the lower occupational security and safety accidents are and vice versa. Workers' low morale and satisfaction, resulted from delayed wages, inadequate housing and psychological discomfort, may increase occupational security and safety accidents, and that is negatively reflected on productivity and production tools.

Hypothesis 4 stated that there is a statistical significant relationship between occupational accidents and the application of occupational safety measures. Results showed that the correlation coefficient value between occupational accidents and the application of occupational safety measures was (0.244), and that the value was positively and statistically significant at (0.01) level. Consequently, the application of occupational safety measures is not sufficient enough to avoid accidents. Furthermore, it is important to spread security and safety culture among employees in order to maximize its positive impact on reducing of occupational accidents in small projects.

Hypothesis 5 stated that there is a statistical significant relationship between improving security and safety level and the use of modern technology. Results revealed that the correlation coefficient value between improving security and safety level and the use of modern technology was (0.951). This high positive value indicates that there is a strong statistical significant correlation between the use of modern technology and improving security and safety level. As a result, using modern technology is highly effective in improving occupational security and safety level in small projects.

Hypothesis 6 stated that there is a statistical significant relationship between occupational accidents and economic and social damages. Results showed the correlation coefficient value between occupational accidents and economic and social damages was (0.501). This value is positive and statistically significant at (0.01) level. Accordingly, the more occupational accidents occur, the higher economic and social damages are. These damages negatively affect the company itself because of financial losses that may lead to bankruptcy. Furthermore, these damages affect not only workers and their families, but also the society as a whole, because of disabling a significant production resource.

Hypothesis 7 stated that there is a statistical significant positive correlation between the effectiveness of the security and safety procedures and fire in small enterprises. Results showed that there is a positive correlation between the effectiveness of the security and safety procedures and fire in small enterprises (0.626). Accordingly, the effective application of security and safety procedures contributes significantly to reducing the occurrence of fires in small enterprises, and vice versa.

Hypothesis 8 stated that there is a positive statistical significant correlation between the effectiveness of security and safety procedures and the external control. Results showed that the correlation coefficient value between the effectiveness of the security and safety procedures (dependent variable) and external control (independent variable) was (0.311). This value is positive and statistically significant. As a result, continuous and strict external control over the application of occupational security and safety procedures contributes to the effectiveness of these procedures. These procedures positively help in maintaining the safety of workers and small enterprises. 
Hypothesis 9 stated that there are no statistical significant differences between participants' responses on occupational security and safety variables due to the difference in their demographic characteristics (age, years of experience and educational qualification).

ANOVA showed that there are statistically significant differences between the means of participants' responses on the application of occupational security and safety procedures, professional training, level of morale, and economic and social damages of occupational accidents, and the total score for the study axes due to the differences in age. On the other hand, results did not indicate any differences in the use of modern technology, which confirms the importance using modern technology for workers.

\subsection{Calculating Direction and Significance of the Differences between Means of the Participants'Responses due to Differences in Age Revealed the Following}

As for the differences related to the application of occupational safety procedures, results showed that the differences are significant in favor of the respondents aged between 41-50 compared to respondents aged less than 30 . As for differences related to workers' training, rehabilitation and morale, results showed that these differences are statistically significant in favor of the respondents aged between 41-50 compared to respondents aged between 51-60, and to those aged under 30. Furthermore, there are differences between respondents aged between 31-40 years compared to those aged less than 30 . As for the differences related economic and social damages, results showed that these differences are in favor of the respondents aged between 41-50 compared to those under 30 . As for the differences at the macro level, results showed that the differences are significant in favor of respondents aged between 31-40 years and those aged between 41-50 compared respondents aged less than 30 . Thus, the majority of the differences are in favor of the respondents aged between 41-50 and those aged between 31-40. This result shows that the workers in these two age categories have a high awareness of occupational accidents in small enterprises.

\subsection{One-way ANOVA Test for the Significance of the Differences between Means of the Participants'Responses due to Differences in Work Experience}

Results of one-way ANOVA test revealed that there are significant differences between the means of participants' responses on employees' technical training, level of morale, and economic and social damages of occupational accidents, and the total score for the study axes due to the differences in work experiences. In addition, results did not indicate differences related to the application of security and safety procedures, and the use of modern technology.

2.12 To Detect the Direction and Significance of Differences due to Differences in Work Experience, the Least Square Difference Test (LSD) was Calculated. Results Showed the Following

Regarding the differences related to workers' technical training and morale, results showed that the differences are significant in favor of employees with more than 5 years of experience compared to employees with less than 5 years of experience.

As for economic and social impacts, results revealed that difference are significant in favor of workers who have 11-20 years of experience compared to both workers who have less than 5 years of experience and workers who have 31-40 years of experience.

Regarding the differences at the macro level, results showed that the differences are in favor of workers with both 11-20 and 21-30 years of experience compared to those with less than 5 years of experience. Results also revealed that differences are significant in favor of workers with 11-20 years of experience compared to those with 31-40 years of experience.

2.13 T-test Results for the Significance of Differences between the Means of Participants' Responses about the Study Axes According to Differences in Academic Qualification

Results of t-test showed that there are no significant differences between participants' responses due to the differences in academic qualification, as the significance of calculated $\mathrm{T}$ values are greater than $(0.05)$. Consequently, the difference in workers' academic qualification is not considered as a factor that leads to differences in their viewpoints about occupational accidents.

\section{Recommendations and Conclusion}

The results of the current study can be summarized in four axes that have been arranged in their order of importance: 


\subsection{First: Workers}

* The researcher noticed, through his work, that some SEs do not pay attention to the rights of foreign workers in terms of protecting the worker and creating a work environment appropriate to him. Foreign workers represent a large proportion of workers in these enterprises. Those workers have a different culture that has a negative impact on work accidents as most of them come from poor countries with low socioeconomic and academic backgrounds. Therefore, it is necessary to take into consideration that they work longer hours than normal work hours without getting paid for the extra hours, and that they get injured due to language barriers and misunderstanding of the safety procedures written in Arabic, if any, or may be forced to do risky work as a result of fear of being sacked. In case of injury, the worker must be treated at the nearest hospital with an accompanying relative and be insured before signing the contract. The administration should abstain from the policy of intimidating employees and the unilateral leadership style. Most of the expatriate workers leave their families in their home countries for long periods of time, and some of them are under intense family pressure (Worsnop, 1995). Caring about those workers has two benefits; it improves worker's productivity and leads to efficient performance of the enterprise. Therefore, they should be trained and protected against accidents and they should know that many of these accidents can be avoided if they are prepared to distance themselves from the philosophy of fatalism (Lingard 2015)

* Determining work hours so that workers do no work more than eight hours per day and forty hours a week. The administration should not ask Saudi workers or expatriate workers to work extra hours unless it is necessary, and they should be compensated, especially those who work in proximity of dangerous places and machinery. Some young workers who are less experienced in dealing with machines are subject to frequent injuries in their early years of work. They work hard and put themselves under stress in anticipation of getting more money, and some of them work on average 2500 hours a year, or more than nine hours and a half a day (52 weeks x 5 Days $\mathrm{x}$ 9.6 hours $=\approx 2500$ hours per year). This leads to a lack of concentration on their work as well as other occupational diseases such as blood pressure, diabetes, heart disease, and psychological stress. These diseases cannot often be compensated materialistically, and they lead to accidents in the workplace. A study conducted in Hong Kong proved that workers who work more than 11 hours a day are constantly susceptible to injury (Dembe et al, 2005).

\subsection{Second: Enterprise Administration}

* It is necessary that the enterprise administration believe in the importance of the means of protecting the employees, extending their knowledge of these means, their contribution to propose new ways to develop the OHS means, investigating their complaints and claims, and benefiting from their intellectual efforts. This will lead to coming up with the best and latest OHS methods and providing the financial resources for them.

* There is a need to disseminate the culture of awareness among the enterprise owners and workers (Fonteyn et al, 1997), and activate the media in the enterprise through films, lectures, publications, posters, magazines, brochures, and instructions (Taha \& Elia, 2012). It is necessary that the administration pay attention to training and qualifying workers so that no worker can operate a new machine without getting the proper training. This is in addition to raising the education level of the owners and workers in SEs to ensure their protection from accidents, developing their skills, and applying the concepts of OHS management and standards of the International Labor Organization (King, 1991).

* It is required of the administration to provide workers with insurance and sign a contract with the nearest hospital to accept cases of injuries and to compensate the worker materialistically and morally. This increases the degree of psychological and functional stability because accidents have a negative impact on workers that leads to low level of job satisfaction and gives workers the feeling that the administration does not care about them.

* Administration should strive for benefiting from modern technology means, providing warning systems and extinguishers, and conducting periodic check on these means. Additionally, it is preferable to connect these means with Civil Defense and cellphone devices of the OHS Supervisor and the SEs' owners.

\subsection{Third: The Supervisor}

* The person responsible for OHS should have high academic qualifications. His responsibilities include monitoring workers in the workplace, applying the administration policies in the field of OHS, rapid intervention in any situation, inspection and testing of machinery and electrical power, maintaining workplace cleanliness, considering workers' suggestions, and doing risk forecasting.

* The supervisor should submit periodic reports, carrying out maintenance of safety means, carrying out follow-up, and preparing medical reports in case of any accident. 
* The supervisor should develop disciplinary measures in case of employees' non-compliance with OHS measures because the risk ratio in SEs is high, and the workers are unwilling to comply with OHS regulations.

\subsection{Fourth: Civil Defense and Government Agencies}

* Civil Defense must oblige SEs to comply with building regulations, install early warning fire systems, use modern storage operations, provide good ventilation and proper lighting, create safe working conditions for workers, and use sufficient number of fire extinguishing means appropriate for each type of fire and train workers on them.

* Official bodies can launch TV programs on OHS and use daily newspapers in spreading the culture of safety by publishing stories of accidents that occur in the workplace. This contributes to the spread of social awareness. In this regard, modern technology and social media tools can be used for sending electronic texts and messages.

* Official bodies can also communicate with local authorities such as, Ministry of Interior, Ministry of Health, Ministry of Education, Engineers Syndicate, specialized professional colleges, hospitals, insurance companies, and regional and international bodies to find out the best ways to reduce accidents and injuries. This can be done by taking advantage of university research studies in the field of OHS, adopting the principles of prediction and prevention, and studying the causes of accidents and the ways to control them.

Finally, there is a need for conducting more research on OHS, especially in the field of SEs in order to reach more profound and more comprehensive results to assess the level of OHS and to know the causes of accidents, especially fires, in terms of personal factors, academic qualifications, experience, wages, requirements of OHS measures, and the amount of financial costs. It is preferable to carry out research on women's OHS in particular, because such research is almost rare in this field.

\section{References}

Abbas, S. (2003). Human Resource Management. First Edition. Amman, Dar Al Shorouq.

Abdul, R. M. (2002). Security and safety in educational buildings: the use of computer in assessing the level of safety in basic education schools. PhD thesis, Cairo University Egypt.

Alhabiyl, W., \& Ayesh, A. (2012). Evaluation of the effectiveness of occupational safety and health procedures in the scientific laboratory from the workers' viewpoint. Gaza

Almoghna, O. (2006). The Reality of Occupational Safety and Security Procedures Used in Manufacturing Industries Sector in the Gaza Strip. Master Thesis, Gaza.

AlSharif, H. (2001). Safety and its relation to the performance of workers in private industrial firms in Dammam. Master thesis, Naif University for Security Sciences, Kingdom of Saudi Arabia.

Aqeelah, M. (2003). Modern Management of Occupational Safety. Second Edition. Amman, Safa Publishing House.

Boussaid, S. (2015). The Role of Occupational Safety and Health Administration in enhancing the Performance of workers in Small and medium Industrial Firms. Master Thesis, Faculty of Economic Sciences, Commercial Sciences and Management Sciences, University of Kasdi Merbah, Ouargla, Algeria.

Cunningham, T. R., Sinclair, R., \& Schulte, P. (2014). Better understanding the small business construct to advance research on delivering workplace health and safety. Small Enterprise Research, 21(2), 148-160. https://doi.org/10.1080/13215906.2014.11082084

DeJoy, D. M., Schaffer, B. S., Wilson, M. G., Vandenberg, R. J., \& Butts, M. M. (2004). Creating safer workplaces: assessing the determinants and role of safety climate. Journal of safety research, 35(1), 81-90. https://doi.org/10.1016/j.jsr.2003.09.018

Dembe, A. E., Erickson, J. B., Delbos, R. G., \& Banks, S. M. (2005). The impact of overtime and long work hours on occupational injuries and illnesses: new evidence from the United States. Occupational and environmental medicine, 62(9), 588-597. Family Violence Prevention Fund, Domestic Violence-A work place Security problem, June 20, 1996. https://doi.org/10.1136/oem.2004.016667

Fonteyn, P. N., Olsberg, D., \& Cross, J. A. (1997). Small business owners' knowledge of their occupational health and safety (OHS) legislative responsibilities. International Journal of Occupational Safety and Ergonomics, 3(1-2), 41-57. https://doi.org/10.1080/10803548.1997.11076364

Fry, E. H. (1990). Not smoking in the workplace: the real issue. Business Horizons, 33(6), 13-17. 
https://doi.org/10.1016/S0007-6813(05)80172-7

Ghamri, N. (2009). Small Enterprises: its management and its indicators of success. 4th edition. Jeddah, Dar Hafez for Publishing and Distribution, Saudi Arabia.

Ghamri, N. (2016). Challenges Facing Businesswomen and Their Negative Impact on the Performance of Small Businesses in The Province of Jeddah in Saudi Arabia. International Journal of Business and Management, $11(9)$.

Ghamri, N. (2016). The Obstacles Facing Young Saudi Men and Women Getting Jobs in Small Businesses Sector. International Journal of Business and social Research, 06(04). http://thejournalofbusiness.org/index.php/site/article/view/954/601

Ghazzawi, M. (2005). Total Quality Management. Amman, Albzuri Scientific publishing house, Jordan. 39-63.

Hasle, P., \& Limborg, H. (2006), A Review of the Literature on Preventive Occupational Health and Safety Activities in Small Enterprises. Industrial Health, 44, 6-12. https://doi.org/10.2486/indhealth.44.6

Heinrich, H. W., Petersen, D. C., Roos, N. R., Brown, J. V., \& Hazlett, S. (1980). Industrial Accident Prevention: A Safety Management Approach: McGraw-Hill.

Holmes, N., Lingard, H., Yesilyurt, Z., \& De Munk, F. (2000). An exploratory study of meanings of risk control for long term and acute effect occupational health and safety risks in small business construction firms. Journal of Safety Research, 30(4), 251-261. https://doi.org/10.1016/S0022-4375(99)00020-1

ILO. (2015). Small and medium-sized enterprises and decent and productive employment creation.

Khalif, S. (2008). Technology and its impact on industrial relations: applied study in cement Badush lab. Technical Journal, 21(6), 308A-323A.

King, B. (1991). Active safety programs. Education Can Help prevent Back Injuries. Occupational Health and Safety, 60(199), 49-51. https://www.ncbi.nlm.nih.gov/pubmed/1832490

Legg, S. J., Olsen, K. B., Laird, I. S., \& Hasle, P. (2015). Managing safety in small and medium enterprises.

Legg, S., Laird, I., Olsen, K., \& Hasle, P. (2014). Creating healthy work in small enterprises-from understanding to action: Summary of current knowledge. Small Enterprise Research: The Journal of SEAANZ, 21 (2), 139. https://doi.org/10.1080/13215906.2014.11082083

Lin, J., \& Mill, A. (2001). Measuring the occupational health and safety performance of construction in Australia, Facilities, 19, 3/4, 131-138. http://www.emeraldinsight.com/doi/pdfplus/10.1108/02632770110381676

Lingard, H. (2015). First Aid and Occupational Health and Safety: The Case for an Integrated Training Approach, Research Gate. Merrily. S. Employer pay when Workers Smoke: Study Business Insurance, 26(1992), 22. http://www.irbnet.de/daten/iconda/CIB559.pdf

Mansouri, Z. \& Nasser, M. (2010). Total Quality Management as an approach to sustain the excellence and competitiveness in business organizations throughout the Algerian economic enterprise experience. The Fourth International Forum on Competition and competitiveness strategies of industrial enterprises outside the petroleum sector in the Arab countries, Algeria.

Moeti-Lysson \& Boy (2011). A study of health and safety practices in small and medium sized enterprises: -A case of Botswana. Journal of Business Management and Economics, 2(3), 125-131.

Naseerat, F. (2007). Total Quality and Institutional Performance: A Survey of administrators' Opinions in some Private Hospitals in the Capital Region Amman / Jordan. Management Sciences Studies, 34(2).

OSHA. (2012). Injury and Illness Prevention Programs.

Park, J., Jeong, H., Hong, S., Park, J. T., Kim, D. S., Kim, J., \& Kim, H. J. (2013). Effects of health and safety problem recognition on small business facility investment. Annals of occupational and environmental medicine, 25(1), 26. https://doi.org/10.1186/2052-4374-25-26

Sabawi, M. (1998). Risk Management: Quantitative Methods. First Edition. Gaza.

Salehawy, S. (2007-2008). Occupational accidents and their effects on the enterprise competitiveness: A case study of Sonelgaz foundation, Biskra Unit. Master thesis, Algeria.

Samih, J. (2001). Training and Preparation of Vocational Training Trainers. Arab Center for Vocational Training and Preparation of Trainees. Amman, Dar Al Shorouk.

Sawacha, E., Naoum, S., \& Fong, D. (1999). Factors affecting safety performance on construction sites. 
International journal of project management, 17(5), 309-315. https://doi.org/10.1016/S0263-7863(98)00042-8

Sekaran, U. (2003). Research Methods for Business: A Skill Building Approach, John Wiley \& Sons, Inc.

Sima, R. (1998). Accidents and Work Injuries: Causes and Approaches of Treatment, Applied Study on Railways. Unpublished master thesis, faculty of commerce, Ain Shams University, Egypt.

Subaie, F. (2013). The extent of satisfaction with the level of security and safety services at the King Fahd Medical City from the respondents' viewpoint. Master thesis, Riyadh, kingdom of Saudi Arabia.

Taha, T., \& Eliah, N. (2012). Occupational safety and health systems in small projects. Assiut Journal of Environmental Studies, 36, Assiut, Egypt.

Thuqan, A., \& Abdul, H. K. (2011). Scientific research; concept, Tools and Methods. Riyadh Saudi Arabia, Dar Osama For Publishing and Distribution.

Tucek, M. (2013). Healthy Working Lives in Healthy Business: New OSH Strategy for Small Enterprises. Cent Eur J Public Health, 21 (3), 174-176. https://www.ncbi.nlm.nih.gov/pubmed/24344546

Walters, D. (1987). Health and safety and trade union workplace organization - a case study in the printing industry. Wiley Online Library, 18(1), 40-49. http://10.1111/j.1468-2338.1987.tb00886.x

Williams, M. F. (1996). Violence and sexual harassment: impact on registered nurses in the workplace. AAOHN journal, 44(2), 73-77. https://www.ncbi.nlm.nih.gov/pubmed/8694978

Worsnop, R. L. (1995). Repetitive Stress Injuries. CQ Researcher, 537-560.

Zein, A. (2009). The guide to the scientific research methodology and writing thesis.2nd edition. University of Khartoum, administrative and technical training and research center press, under the supervision of Arabization Management.

\section{Copyrights}

Copyright for this article is retained by the author(s), with first publication rights granted to the journal.

This is an open-access article distributed under the terms and conditions of the Creative Commons Attribution license (http://creativecommons.org/licenses/by/4.0/). 